\title{
Analysis of 75 consecutive COVID-19 ECMO cases in Warsaw Centre for Extracorporeal Therapies
}

\author{
Piotr Suwalski*, Dominik Drobiński*, Radosław Smoczyński', Marzena Franczyk', Wojciech Sarnowski', Agnieszka \\ Gajewska', Anna Witkowska', Waldemar Wierzba²,3, Artur Zaczyński , Zbigniew Król², Konstanty Szułdrzyński', \\ Robert Gałązkowski', Wojciech Nowak', Mateusz Konstantynowicz', Maciej Dąbrowski', Andrzej Rydzewski', Maciej \\ Bartczak' , Maciej Puchniewicz' , Tomasz Apel ${ }^{5}$, Mariusz Kowalewski ${ }^{1}$, 8,9, Jakub Staromłyński
}

\begin{abstract}
'Department of Cardiac Surgery, Central Clinical Hospital of the Ministry of Interior, Centre of Postgraduate Medical Education, Warszawa, Poland ${ }^{2}$ Central Clinical Hospital of the Ministry of the Interior and Administration in Warsaw, Warszawa, Poland

${ }^{3}$ Satellite Campus in Warsaw, University of Humanities and Economics in Lodz, Warszawa, Poland

${ }^{4}$ Clinical Department of Neurosurgery, Central Clinical Hospital of the Ministry of the Interior and Administration in Warsaw, Warszawa, Poland ${ }^{5}$ Department of Anesthesiology and Intensive Care, Central Clinical Hospital of the Ministry of the Interior and Administration, Warszawa, Poland

${ }^{6}$ Clinical Department of Nephrology, Central Clinical Hospital of the Ministry of the Interior and Administration in Warsaw, Warszawa, Poland ${ }^{7}$ Department of Emergency Medical Service, Medical University of Warsaw, Warszawa, Poland

${ }^{8}$ Cardio-Thoracic Surgery Department, Heart and Vascular Centre, Maastricht University Medical Centre, Maastricht, Netherlands

${ }^{9}$ Thoracic Research Centre, Collegium Medicum, Nicolaus Copernicus University, Innovative Medical Forum, Bydgoszcz, Poland

*Both authors equally contributed to the study
\end{abstract}

Correspondence to:
Mariusz Kowalewski,
MD, PhD,
Clinical Department of
Cardiac Surgery,
Central Clinical Hospital of
the Ministry of Interior and
Administration,
Centre of Postgraduate
Medical Education,
Wołoska 13,02-507
Warszawa, Poland,
phone: +48 502269249,
e-mail:
kowalewskimariusz@
gazeta.pl
Copyright by the
Author(s), 2021
Kardiol Pol. 2021;
79 (7-8): 851-854;
DOI: 10.33963/KP.a2021.0011
Received:
April 14, 2021
Revision accepted:
May 14, 2021
Published online:
May 18, 2021

Correspondence to:

Mariusz Kowalewski,

Cardiac Surgery

Central Clinical Hospital of

Ministry of Interior and

Medical Education,

Wołoska 13, 02-507

Warszawa, Poland

e-mail:

kowalewskimariusz@

gazeta.pl

Copyright by the

Kardiol Pol. 2021

79 (7-8): 851-854;

DO|: 10.33963/KP.a2021.0011

Revision accepted

May 14, 2021

May 18, 2021

\section{INTRODUCTION}

The spread of severe acute respiratory syndrome coronavirus 2 (SARS-CoV-2) has become a rapidly devastating global pandemic. Veno-venous extracorporeal membrane oxygenation (V-VECMO) may be a highly effective and lifesaving therapy for acute refractory respiratory failure (ARRF) in the context of acute respiratory compromise such as that induced by SARS-CoV-2. Recent studies indicate that there is a $35 \%-50 \%$ mortality rate for critically ill patients. However, since the increased prevalence of the British variant strain of COVID-19, patient mortality while on extracorporeal circulation has increased dramatically. This is despite the growing medical experience with COVID-ECMO, previous ECMO therapies, patient selection, and the objectively lower number of serious complications caused by therapy [1]. The study aims to outline the differences between COVID-ECMO during the first and next waves of the pandemic, with a particular interest in mortality, patient characteristics, and referral destination. The current study was not subjected to review by a bioethical committee. The data are anonymous, retrospectively collected, and derived from a single-center registry.

Having predicted the necessity to support patients critically ill with COVID-19 ARRF with
V-V ECMO, and in order to make optimal use of the expertise and resources of the Clinical Department of Cardiac Surgery (Central Clinical Hospital of the Ministry of Interior and Administration), this study founded The Centre for Extracorporeal Therapies (CET) at the beginning of the pandemic, on March $20^{\text {th }}, 2020$. The CET has since been serving as a subunit of the Clinical Department of Cardiac Surgery, using the expertise of cardiac anesthetists, cardiac surgeons, cardiologists, perfusionists, and intensivists and admitting patients from the entire voivodeship and beyond. Recently, due to the growing number of patients requiring extracorporeal therapy, the CET has expanded and now includes the general Department of Anesthesiology and Intensive Care (Central Clinical Hospital of the Ministry of Interior and Administration).

The CET team also established the mobile-ECMO team for patients experiencing mobility barriers. This team involving an anesthetist, cardiac surgeon, and perfusionist to ensure complications can be safely addressed while en-route to the CET. In close cooperation with the Polish Medical Air Rescue service and Emergency Medical Services (EMS), this study also established dispatch and transport procedures for ECMO-dependent patients. 


\section{METHODS}

The registry included all 75 consecutive cases of COVID-ECMOs admitted to our department between March $20^{\text {th }}, 2020$ to March $20^{\text {th }}, 2021$. Patients were candidates for ECMO therapy if they tested positive for COVID-19 or displayed a history of having contracted COVID-19. Patients also had to have met the criteria for ECMO support in ARRF as described by the Board of Intensive Care document and adopted by the Agency for Health Technology Assessment and Tariff System (AOTMIT) [2]. This study was approved by the Institutional Review Board but patient consent for inclusion in the registry was waived. Transesophageal echocardiography (TEE) was performed to assess ventricular function and determine the positioning of the ECMO cannulas. All patients underwent computed tomography to determine the extent of pulmonary involvement. When a transition to veno-arterial (V-A) ECMO was necessary, the ECMO heart team would meet this identified need.

Early mortality was defined as mortality (of any cause) during the index hospitalization or within 30 days of admission. Complications were identified through the application of institutional protocols and definitions.

This study examined patients that were treated in the first wave (March 20 ${ }^{\text {th }} 2020-J u l y ~ 30^{\text {th }} 2020$ ) vs the next waves (August $1^{\text {st }} 2020-M a r c h ~ 20^{\text {th }} 2021$ ) as per epidemic Renormalisation Group temporal definition [3]. Mean \pm standard deviations (SD) were used for normally distributed variables, while for non-normal distributions median and interquartile range (IQR) were used and compared with the Mann-Whitney $U$ test or standard $t$ test as appropriate. A two-tailed $P$-value of $<0.05$ was considered significant. STATA MP 13.0 (StataCorp, College Station, TX) was used for data analyses.

\section{RESULTS AND DISCUSSION}

Seventy-five patients (15 [20.0\%] women) underwent ECMO therapy to address COVID-19 symptoms; 16 (21.3\%) were treated between March $20^{\text {th }}, 2020$ and July $30^{\text {th }}$ 2020 and the remaining 59 (78.7\%) were treated between August $1^{\text {st }} 2020$ and March $20^{\text {th }}, 2021$. The prevalence of ARRF was the primary consideration for the application of ECMO therapy for all patients. Concomitant symptoms considered for the application of V-V ECMO therapy included sepsis (1 case), massive pulmonary embolism (1 case) and pulmonary PISZEMY AmEng edema (1 case). One patient presented with malignant ventricular arrhythmia and V-A ECMO. In 23 patients (30.6\%), ECMO was applied offsite and patients were later transferred to the CET Warsaw location. Eight patients reached CET by air (Figure 1).

The mean age of patients treated before August $1^{\text {st }}$, 2020 was 53.6 years (SD 9.3) and was significantly higher than this of patients treated after August 1 ${ }^{\text {st }}, 2020$ (46.8 [SD 8.5]); $P=0.007)$. The median duration from ventilator use to ECMO therapy was 7 (IQR [3-9]) days in the first temporal group vs 5 days (IQR [2-7]) in the second temporal group. However, this difference was not significant. The mean duration of ECMO therapy was 11 days (SD 6.8) in the first temporal group and 18 days (SD, 7.3$)$ in the second $(P$ $<0.001)$. Ten patients $(62.5 \%)$ were successfully weaned and survived to discharge in the first temporal group. As of March 29th 2021 , 40 patients died in the second group; of those, 3 after having been weaned from support, translating into $40.7 \%$ weaning and $32.2 \%$ survival rates respectively. Twelve ECMOs are currently operating (10 Cardiohelp [Maquet Cardiovascular, Bridgewater, NJ], 1 RotaFlow [Maquet Cardiovascular, Bridgewater, NJ], 1 LivaNova ECC [LivaNova PLC, London, UK] in ECMO setup) (Supplementary material, Video S1). Eight patients were listed for lung transplantation; of those, 4 patients received referrals to a lung transplant center and 4 underwent successful lung transplantation.

Our preliminary data suggest that patients with severe refractory respiratory or cardiac failure due to COVID-19 and who were placed on ECMO therapy had a reasonable (62.5\%) chance of survival during the first wave of the COVID-19 pandemic. The majority of these individuals could have been successfully discharged from ECMO therapy. During the first wave of therapy, we introduced the mobile COVID-ECMO therapy resource, which continues to be among the most active in Poland, able to apply ECMO therapy off-site and transport patients to the extracorporeal therapy hub. Air medical services provided by the Polish Medical Air Rescue - and by police and military air forces - supported logistics and patient transfer to and from remote site locations and, more recently, supported the transfer of patients to lung-transplant referral centers.

It is significant to note that this study was the first to introduce an ECMO-heart team, a team of professionals including a cardiac surgeon, perfusionist, cardiac anesthetist, cardiologist, and intensivists together with the supportive work of an intensive-care and anesthetist nurse. The cardiologist was a highly valuable addition to the team for various reasons. Peripheral V-V ECMO takes over the pulmonary function of blood oxygenation; by doing so, blood $\mathrm{SO}_{2}$ is no longer representative of deteriorating heart conditions and RV failure. Routine echocardiographic check-ups help to determine the optimal time to upgrade the V-VECMO circuit to more advanced configurations, such as V-VV, V-VA, VA-V, orV-VVA. This transition is needed in order to better address a failing RV, avoid differential hypoxia, and react to a patient's rapidly changing health conditions. In addition, optimal anticoagulation poses a major challenge for COVID-19 patients undergoing ECMO therapy, due to increased risk of thrombosis, bleeding, and other coagulation disorders [4].

A recent report from the Extracorporeal Life Support Organization (ELSO) Registry aimed to characterize the epidemiology, hospital course, and outcomes of patients aged 16 years or older with confirmed cases of COVID-19 and who underwent ECMO therapy between January $16^{\text {th }}$, and May $1^{\text {st }}, 2020$ at 213 hospitals in 36 countries. The report found that the estimated mortality of patients 90 days after undergoing ECMO therapy was less than 40\% [1], 


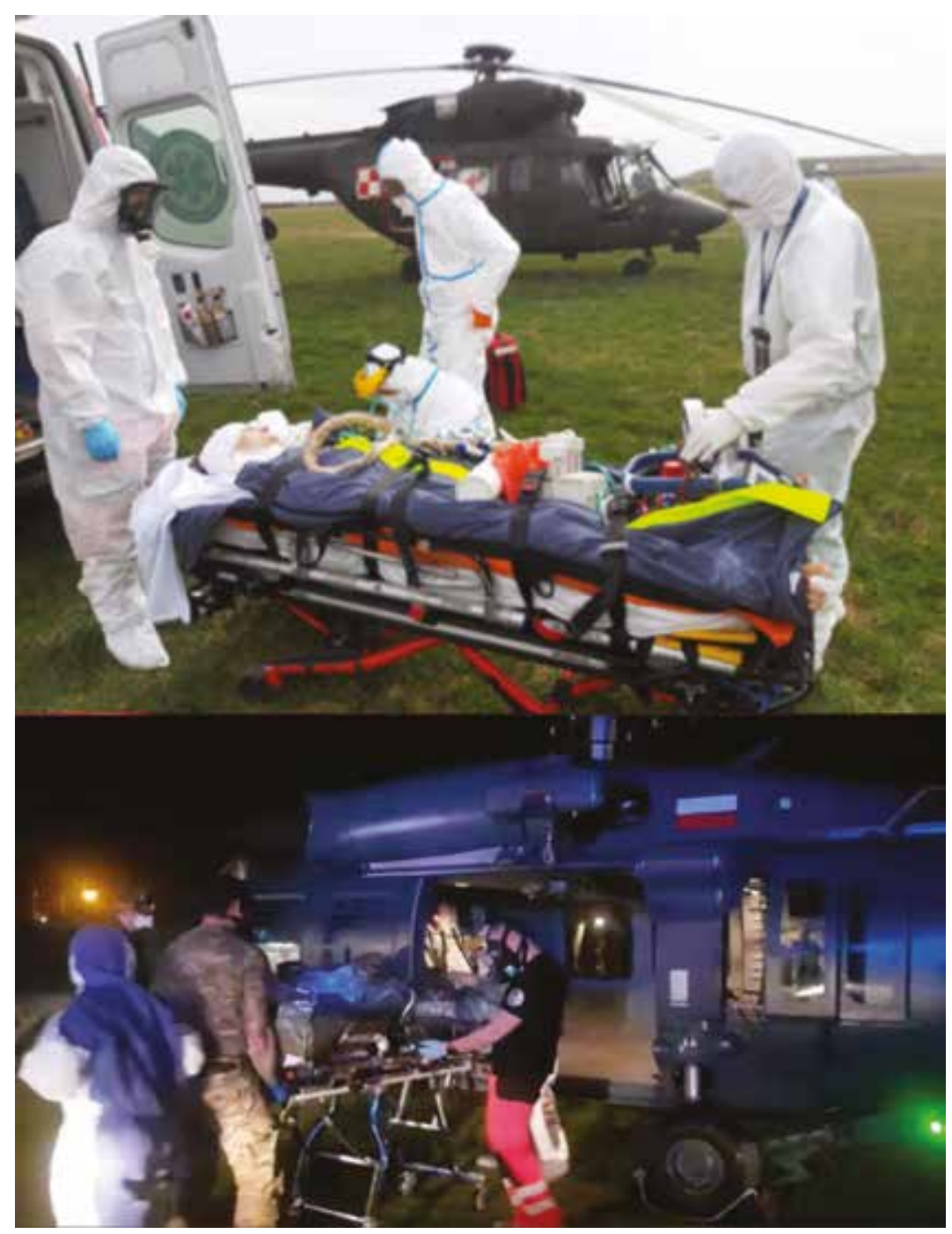

Figure 1. Air medical transport of ECMO patient

aligning with the results of this study regarding the first wave. More recently, the ELSO survey presented less encouraging results. A trend toward increased mortality has been observed across European countries and also reported in a systematic review which found mortality rate in adult patients with COVID-19 on ECMO of about 75\% [5] attributable, in part, to novel strains of COVID-19 leading to higher infection rates, more severe manifestations and more COVID-19 hospitalizations and deaths among younger individuals. Additional data analysis is needed to provide information on the demographics, severity of illness, symptoms, and different ECMO therapy management strategies in these patients.

\section{CONCLUSIONS}

ECMO is a valuable tool in the treatment of COVID-19 patients presenting with acute respiratory insufficiency refractory to other supportive measures. The trends are changing, however, with regards to patient profile, destination therapy and predicted mortality, with younger patients being admitted, higher observed mortality and the in- creasing number of candidates for lung transplantation as destination therapy. COVID-19 pandemic required that ECMO-patient transport procedures are formally and practically implemented. Done so, we believe these may serve critically ill patients in the future.

\section{Supplementary material}

Supplementary material is available at https://journals. viamedica.pl/kardiologia_polska.

\section{Article information}

Acknowledgements: The authors wish to acknowledge the tremendous amount of work put in the daily struggle with critically ill COVID-19 patients at the Central Clinical Hospital of the Ministry of the Interior and Administration in Warsaw.

Conflict of interest: None declared.

Open access: This article is available in open access under Creative Common Attribution-Non-Commercial-No Derivatives 4.0 International (CC BY-NC-ND 4.0) license, allowing to download articles and share them with others as long as they credit the authors and the publisher, but without permission to change them in any way or use them commercially. For commercial use, please contact the journal office at kardiologiapolska@ptkardio.pl. 
How to cite: Suwalski P, Drobiński D, Smoczyński R, et al. Analysis of 75 consecutive COVID-19 ECMO cases in Warsaw Centre for Extracorporeal Therapies. Kardiol Pol. 2021; 79(7-8): 851-854, doi: 10.33963/KP.a2021.0011.

\section{REFERENCES}

1. Barbaro RP, MacLaren G, Boonstra PS, et al. Extracorporeal membrane oxygenation support in COVID-19: an international cohort study of the Extracorporeal Life Support Organization registry. Lancet. 2020; 396(10257): 1071-1078, doi: 10.1016/50140-6736(20)32008-0, indexed in Pubmed: 32987008.

2. Niżankowski R, Myśliwiec M, Szymański P, et al. COVID-19 recommendations. Polish diagnostic, therapeutic and organisational recommen- dations for the care of individuals infected with SARS-CoV-2 or exposed to a SARS-CoV-2 infection. www.aotm.gov.pl/media/2020/07/Covid_FINAL-v-1.1-_wersja-EN-1.pdf. [April 14, 2021].

3. Cacciapaglia G, Cot C, Sannino F. Second wave COVID-19 pandemics in Europe: a temporal playbook. Sci Rep. 2020; 10(1): 15514, doi: 10.1038/s41598-020-72611-5, indexed in Pubmed: 32968181.

4. Kowalewski M, Fina D, Słomka A, et al. COVID-19 and ECMO: the interplay between coagulation and inflammation-a narrative review. Crit Care. 2020; 24(1): 205, doi: 10.1186/s13054-020-02925-3, indexed in Pubmed: 32384917.

5. Suwalski $P$, Rydzewski $A$, Wójtowicz $R$, etal. Severe respiratory failure in the course of coronavirus disease 2019 treated with extracorporeal membrane oxygenation. Kardiol Pol. 2020; 78(9): 913-915, doi: 10.33963/KP.15444, indexed in Pubmed: 32598104 